International Journal of Solar Thermal Vacuum Engineering

Journal homepage: https://akademiabaru.com/submit/index.php/stve/index ISSN: 2716-6953

\title{
Enhancing the renewable energy payback period of a photovoltaic power generation system by water flow cooling
}

\author{
Ali Sohani $i^{1,}{ }^{*}$, Mohammad Hassan Shahverdian ${ }^{1}$, Hoseyn Sayyaadi ${ }^{1}$, Siamak Hoseinzadeh ${ }^{2}$, Saim \\ Memon ${ }^{3, *}$ \\ 1 Lab of Optimization of Thermal Systems' Installations, Faculty of Mechanical Engineering-Energy Division, K.N. Toosi University of Technology, \\ P.O. Box: 19395-1999, No. 15-19, Pardis St., Mollasadra Ave., Vanak Sq., Tehran 1999 143344, Iran \\ 2 Department of Planning, Design, and Technology of Architecture, Sapienza University of Rome, Via Flaminia 72, 00196, Rome, Italy \\ 3 Solar Thermal Vacuum Engineering Research Group, London Centre for Energy Engineering, School of Engineering, London South Bank \\ University, London, United Kingdom
}

\section{ABSTRACT}

A photovoltaic system which enjoys water flow cooling to enhance the performance is considered, and the impact of water flow rate variation on energy payback period is investigated. The investigation is done by developing a mathematical model to describe the heat transfer and fluid flow. A poly crytalline PV module with the nomical capacity of $150 \mathrm{~W}$ that is located in city Tehran, Iran, is chosen as the case study. The results show that by incresing water flow rate, EPBP declines first linearly, from the inlet water flow rate of 0 to $0.015 \mathrm{~kg} \cdot \mathrm{s}^{-1}$, and then, EPBP approaches a constant value. When there is no water flow cooling, EPBP is 8.88 , while by applying the water flow rate of $0.015 \mathrm{~kg} . \mathrm{s}^{-1}$, EPBP reaches 6.26 years. However, only 0.28 further years decreament in EPBP is observed when the inlet water mass flow rate becomes $0.015 \mathrm{~kg} . \mathrm{s}^{-1}$. Consequently, an optimum limit for the inlet water mass flow rate could be defined, which is the point the linear trend turns into approaching a constant value. For this case, as indicated, this value is $0.015 \mathrm{~kg} \cdot \mathrm{s}^{-1}$.

\section{Keywords:}

Efficiency improvement way; Energy payback period; Parametric study; Photovoltaic (PV) technology; Water-flow cooling technique

\section{Introduction}

There is a strong tendency to replace the fossil fuels with renewable energies, which is motivated by the need to have safer, cleaner, and more available supply [1,2]. This reality could necessarily transition our built environment, such as office buildings and residential buildings, towards renewable energy sources [3,4]. As the concept of GEB (Generating Energy Buildings) has now becoming a reality in which a series of innovative technologies such as translucent vacuum insulation panels [5-7], smart vacuum insulated windows [8-25], vacuum-based PV integrated solar thermal collectors [26,27] and cooling mechanism [28], wind \& wave energy systems [29], providing access

\footnotetext{
* Corresponding author.

E-mail address: alisohany@yahoo.com; asohani@mail.kntu.ac.ir (A.Sohani); S.Memon@lsbu.ac.uk (S.Memon)
} 
and monitoring of the electric vehicles charging [30-34] with integration to microgrid [35] and utilising waste heat into electricity using thermoelectric [36-39] are the progress towards smart cities. It is evident from the aforementioned references that solar thermal energy and insulation technologies are playing major role in achieving the built environment sector towards net-zero energy.

As one of the most popular kinds of renewable energies, solar energy is predicted to play a serious role in the future [40]. However, the concepts of carbon capture-storage and progressive technologies of quantum-dot and organic solar cells and new materials $[41,42]$ are going to speed up the notion of GEB [43]. Still, using PV modules offers a number of huge benefits that makes it favorable worldwide. It originates from the issues like being utilized in different scales, as well as low cost compared to other products to provide the electrical energy [44]. Among different types of PV technologies, the silicone based (Si-based) type is the most available type in the market. The main reason is the low cost of that compared to the other kinds.

Silicon modules typically convert around $20 \%$ of solar energy into electricity, and the rest is converted into heat. This heat causes the module temperature to rise. As the module heats up, its performance decreases and its efficiency decreases. Considering this point, cooling solar modules is one of the ways to increase efficiency. One of the common cooling methods is cooling the surface of the module by pouring water. Water has a high heat absorption capacity due to its high heat capacity and further reduces the surface temperature of the module.

The following is the research conducted in this regard:

Javidan and Moghadam [45] investigated the effect of cooling on the photovoltaic module by jet impingement cooling with water-acting fluid. They examined the number of nozzles and their diameters. Finding the optimal conditions, they found that the temperature of the solar module drops from $63.95^{\circ} \mathrm{C}$ to $33.68^{\circ} \mathrm{C}$.

Shahverdian et al. [46] used water flow system for cooling the solar module. They optimized the hourly water flow and found that the difference in average cell surface temperature for a cooling system with an optimal flow rate compared to a system with a constant flow rate without cooling in the module was $16.63^{\circ} \mathrm{C}$ and $54.07^{\circ} \mathrm{C}$, respectively.

Da Silva et al. [47] investigated the effect of water film cooling on the solar module and found that this method reduces the panel temperature by about 15 to $19 \%$.

Luben et al. [48] Experimentally studied the cooling effect on a 240W polycrystalline module. In this research, cooling has been done by pouring water and also spraying it. The effect of this cooling on current and voltage has been seen.

Kabeel et al. [49] in an experimental study investigated the effect of cooling and using reflector on a photovoltaic solar module. The cooling method in this article is water flow as well as air blower. Experimental results show that the net power for the mode without cooling and using the reflector is 832 Wh.day ${ }^{-1}$ and for the mode with reflector and air blower, with reflector and water flow and for the mode with reflector and air blower and water flow, it is 912, 1077 and 1010 Wh.day ${ }^{-1}$.

Tashtoush and Oqool [50] experimentally investigated the effect of cooling by water flow. In this work, an attempt has been made to keep the temperature of the module at a specific temperature, 
which in this study is $35^{\circ} \mathrm{C}, 37^{\circ} \mathrm{C}, 39^{\circ} \mathrm{C}, 41{ }^{\circ} \mathrm{C}, 43^{\circ} \mathrm{C}$ and $45^{\circ} \mathrm{C}$, and to examine the amount of water consumption at each of these temperatures and the rate of increase in power.

Maj et al. [51] cooled down a $260 \mathrm{~W}$ module by dropping water. For their work, they identified 9 points on the solar module and observed the effect of cooling on the temperature of these points through thermal imaging and compared the power of the module in both cooling and non-cooling modes in different radiation.

Basrawi et al. [52] conducted experimental work in the laboratory to study the cooling of the photovoltaic solar module by water cooling. Cooling analysis was investigated in three ways: without module cooling, half surface and all cooled surface. This effect is observed on the parameters of temperature, current, voltage and power.

Nazetic et al. [53] analyzed the cooling effect by spraying water on the front and back of the module. In this work, they obtained the module temperature in the state without cooling and with cooling of the back and front, $54{ }^{\circ} \mathrm{C}$ and $24^{\circ} \mathrm{C}$, respectively.

Reviewing literature shows that although different energy-related important performance criteria of a PV system with water flow cooling have been investigated so far, only efficiency has been considered as a dimensionless index. In other words, other dimensionless performance indicators of such system have not been investigated. Therefore, and based on the indicated gap, in this study, energy payback period, as a recently developed concept is chosen, and the impact of changing water flow rate on that is investigated through the parametric study.

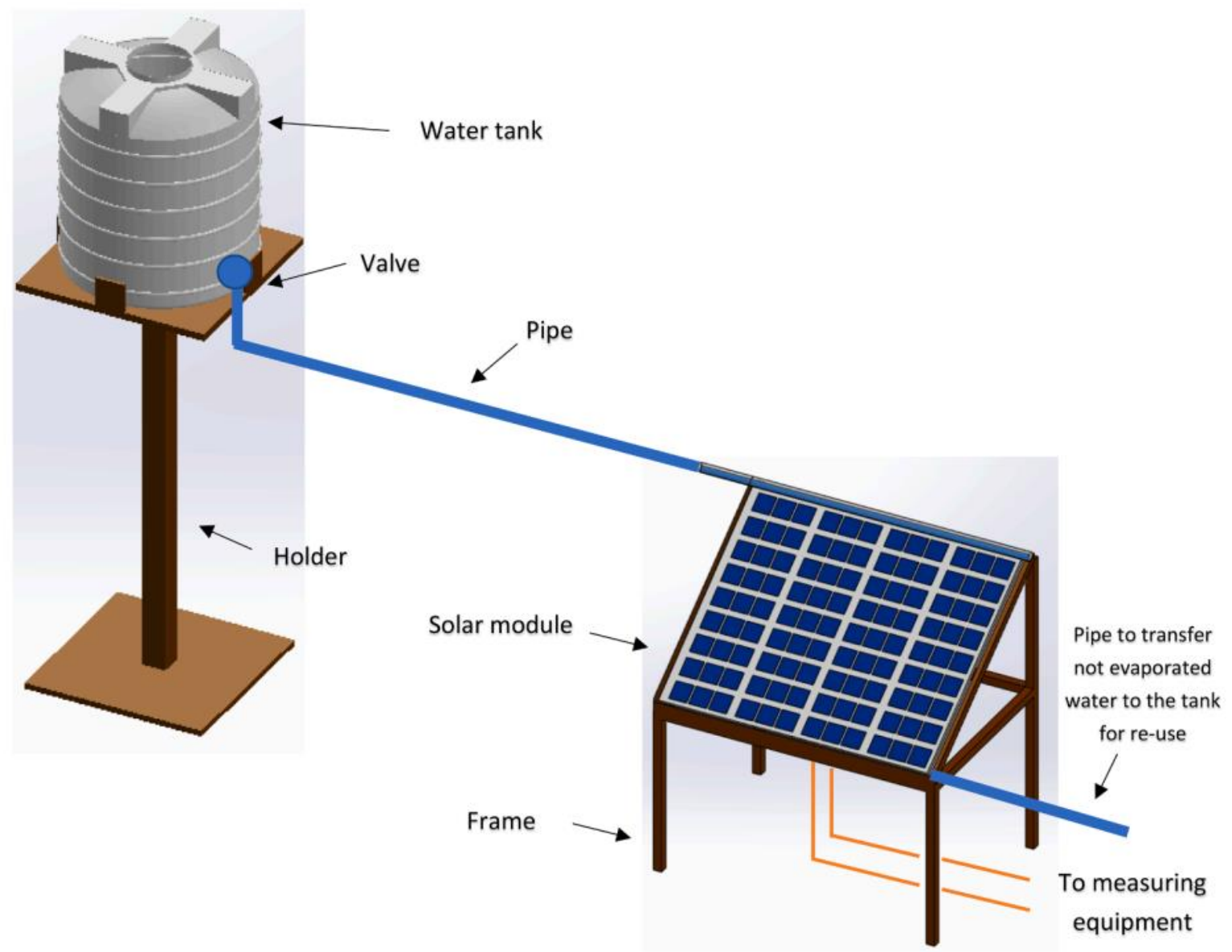

Fig. 1. The experimental setup employed in this study to record data [46] 


\section{The PV power generation system with water flow cooling}

Fig. 1 introduces the studied PV power generation system. As observed, in this system, water flows on the surface of PV module and through absorbing the water, the PV module cools down, and a part of water is evaporated. The not evaporated water is returned to the tank for using again. The water flow rate could be controlled using a valve, while the tank, which keeps the water, is installed on a holder, same as the PV module.

\section{Modelling}

This part gives the details of modelling. Initially, in section3.1, description of modelling from heat transfer and fluid flow aspects is presented. Then, part 3.2 explains that how energy payback period is calculated.

\subsection{Heat transfer and fluid flow}

In this section, the modeling of water flow on a photovoltaic solar module is discussed. To achieve this, in the first part, the equations governing each layer are given and in the next part, the thermal resistances in each layer are discussed.

\subsubsection{Energy balance equation}

In this section, 6 layers of water, glass, upper EVA, silicon, bottom EVA and tedlar are modeled. The equations are extracted from the literature; including the previous studies of the research team $[54,55]$.

a) Water layer

The upper layer is the water layer that flows on the solar module. In Eq.(1), the energy balance equation for this layer is written:

$$
m_{w} c_{p, w} \frac{d T_{w}}{d t}=\alpha_{w} G A+\frac{T_{g}-T_{w}}{R_{c o n v-g, w}}-\frac{T_{w}-T_{a}}{R_{\text {evap }}}-\frac{T_{w}-T_{a}}{R_{\text {conv-w,a }}}-\frac{T_{w}-T_{\text {sky }}}{R_{\text {rad }-w, \text { sky }}}+\dot{m}_{w} c_{p, w}\left(T_{\mathrm{s}}-T_{w}\right)
$$

Where $m_{w}$ is the mass of water, $c_{p, w}$ is the water specific heat, $T_{w}$ is the water temperature, $t$ is the time, $\alpha_{w}$ is the water absorptivity, $G$ is the irradiation, $A$ is the area of module, $T_{g}$ is the glass temperature, $R_{c o n v-g, w}$ is the convective thermal resistance between water and glass, $T_{a}$ is the ambient temperature, $R_{\text {evap }}$ is the evaporative thermal resistance, $R_{\text {conv-w,a }}$ is the convective thermal resistance between water and ambient, $T_{s k y}$ is the sky temperature and $R_{\text {rad }-w, \text { sky }}$ is the radiative thermal resistance of water.

b) Glass layer

The next layer is the glass layer, whose energy balance equation is given in Eq.(2): 


$$
c_{p, g} \delta_{g} A \rho_{g} \frac{d T_{g}}{d t}=\alpha_{g} \tau_{w} G A-\frac{T_{g}-T_{w}}{R_{c o n v-g, w}}+\frac{T_{E V A l}-T_{g}}{R_{E V A l, g}}
$$

Where $c_{p, g}$ is the glass specific heat, $\delta_{g}$ is the glass thickness, $\rho_{g}$ is the glass density, $T_{g}$ is the glass temperature, $\alpha_{g}$ is the glass absorptivity, $\tau_{w}$ is the water transitivity, $T_{E V A l}$ is the upper EVA temperature and $R_{E V A l, g}$ is the conductivity thermal resistance between upper EVA and glass.

c) Top EVA layer

The energy balance of the upper EVA layer is seen in Eq. (3):

$$
c_{p, E V A 1} \delta_{E V A 1} A \rho_{E V A 1} \frac{d T_{E V A 1}}{d t}=\frac{T_{P V}-T_{\mathrm{EVAl}}}{R_{P V, E V A 1}}-\frac{T_{E V A 1}-T_{g}}{R_{E V A l, g}}
$$

In above equation, $c_{p, E V A 1}$ is the upper EVA specific heat, $\delta_{E V A 1}$ is the upper EVA thickness, $\rho_{E V A 1}$ is the upper EVA density, $T_{P V}$ is the silicon temperature and $R_{P V, E V A 1}$ is the conductivity thermal resistance between upper EVA and silicon layer.

d) Silicon layer

The energy balance equation of the silicon layer, which is responsible for converting heat energy into electricity, is given in Eq.(4):

$$
c_{p, \mathrm{PV}} \delta_{P V} A \rho_{P V} \frac{d T_{P V}}{d t}=\alpha_{P V} \tau_{g} \tau_{w} G A-P_{e l e}-\frac{T_{P V}-T_{\mathrm{EVA} 1}}{R_{P V, E V A 1}}-\frac{T_{P V}-T_{\mathrm{EVA} 2}}{R_{E V A 2, P V}}
$$

Where $c_{p, \mathrm{PV}}$ is the silicon specific heat, $\delta_{P V}$ is the silicon thickness, $\rho_{P V}$ is the silicon density,,$\alpha_{P V}$ is the silicon absorptivity, $\tau_{g}$ is the glass transitivity, $P_{e l e}$ is the electricity production of module, $T_{\mathrm{EVA} 2}$ is the bottom EVA temperature and $R_{E V A 2, P V}$ is the conductivity thermal resistance between bottom EVA and silicon layer.

e) Bottom EVA layer

As Eq.(3) for the upper EVA layer is written for this layer:

$$
c_{p, E V A 2} \delta_{E V A 2} A \rho_{E V A 2} \frac{d T_{E V A 2}}{d t}=\frac{T_{P V}-T_{\mathrm{EVA} 2}}{R_{E V A 2, P V}}-\frac{T_{E V A 2}-T_{T d}}{R_{E V A 2, T d}}
$$

In Eq.(5), $c_{p, E V A 2}$ is the bottom EVA specific heat, $\delta_{E V A 2}$ is the bottom EVA thickness, $\rho_{E V A 2}$ is the bottom EVA density, $T_{T d}$ is the tedlar temperature and $R_{E V A 2, T d}$ is the conductivity thermal resistance between bottom EVA and tedlar layer.

f) Tedlar layer

The energy balance equation of the substrate of a photovoltaic module, which is the ted layer, is shown in Eq.(6):

$$
c_{p, \mathrm{Td}} \delta_{T d} A \rho_{\mathrm{Td}} \frac{d T_{\mathrm{Td}}}{d t}=\frac{T_{E V A 2}-T_{T d}}{R_{E V A 2, T d}}-\frac{T_{T d}-T_{a}}{R_{\text {conv-Td,a }}}-\frac{T_{T d}-T_{g r}}{R_{r a d-T d, \mathrm{gr}}}
$$


Where $c_{p, \mathrm{Td}}$ is the tedlar specific heat, $\delta_{T d}$ is the tedlar thickness, $\rho_{\mathrm{Td}}$ is the tedlar density, $R_{\text {conv-Td,a }}$ is the convective thermal resistance between tedlar and ambient, $T_{g r}$ is the ground temperature and $R_{r a d-T d, \text { gr }}$ is the radiative thermal resistance of tedlar.

\subsubsection{Thermal resistance}

As mentioned above, this section deals with thermal resistance relationships.

a) Conductive thermal resistance

The conductive thermal resistance in the solar module is between the layers of glass, upper EVA, silicon, bottom EVA and tedlar, which is given in Eq.(7) in general.

$$
R_{\mathrm{a}, \mathrm{b}}=\frac{\delta_{a}}{2 k_{a} A_{a}}+\frac{\delta_{b}}{2 k_{b} A_{b}}
$$

In the above equation, $k$ is the thermal conductivity.

b) Convective thermal resistance

Eq.(8) is used to calculate the displacement thermal resistance.

$$
R_{c o n v-g, w}=\frac{1}{h_{c o n v} A}
$$

Where $h_{\text {conv }}$ is the heat transfer coefficient which is given in Eqs (9) and (10).

$$
\begin{aligned}
& h_{\text {conv }-g, w}=0.332 \operatorname{Re}^{0.5} \operatorname{Pr}^{0.33} \\
& h_{\text {conv }-T d, a}=h_{\text {conv }-g, a}=2.8+3 U
\end{aligned}
$$

c) Radiative thermal resistance

The radiative thermal resistance between the water layer and the air as well as the tedlar and the ground are given in Eqs (11) and (12), respectively.

$$
\begin{aligned}
& R_{r a d-w, s k y}=\frac{1}{\sigma \varepsilon_{w} A\left(T_{w}^{2}+T_{s k y}^{2}\right)\left(T_{w}+T_{s k y}\right)} \\
& R_{r a d-T d, \mathrm{gr}}=\frac{1}{\sigma \varepsilon_{T d} A\left(\mathrm{~T}_{T d}^{2}+\mathrm{T}_{g r}^{2}\right)\left(\mathrm{T}_{\mathrm{Td}}+\mathrm{T}_{\mathrm{gr}}\right)}
\end{aligned}
$$

Where $\sigma$ is the Stefan-Boltzmann and $\varepsilon$ is the emissivity. In Eq.(11), $T_{s k y}$ is calculated as Eq.(13)

$$
\mathrm{T}_{\text {sky }}=0.0552 T_{a}^{1.5}
$$

\section{d) Evaporative thermal resistance}

To calculate the heat transfer resulting from water evaporation, the evaporative thermal resistance must be determined, which is obtained according to Eqs. (14) to (17). 


$$
\begin{aligned}
& R_{\text {evap }}=\frac{1}{h_{\text {evap }} A} \\
& h_{\text {evap }}=\frac{0.016\left(\mathrm{P}_{\mathrm{w}}-\varphi P_{\mathrm{a}}\right)}{T_{w}-T_{a}} \\
& \mathrm{P}_{\mathrm{w}}=\exp \left(25.317-\frac{5144}{T_{\mathrm{w}}}\right) \\
& \mathrm{P}_{a}=\exp \left(25.317-\frac{5144}{T_{a}}\right)
\end{aligned}
$$

Where $\varphi$ is the relative humidity, and $P$ is the partial pressure.

\subsubsection{Electrical model}

There are various methods and formulas for calculating the amount of electricity generated in the solar module. In one of these methods, holding the temperature of the solar module, the efficiency of the module is calculated, which is seen in Eq.(18), and then having the efficiency of the module, its power is calculated according to Eq.(19) [56].

$$
\begin{aligned}
& \eta_{\text {elec }}=\eta_{\text {ref }}\left(1-\beta_{\text {ref }}\left(T_{P V}-T_{\text {ref }}\right)\right) \\
& P_{\text {elec }}=\eta_{\text {elec }} G A
\end{aligned}
$$

\subsection{Calculating the energy payback period}

Energy payback period, which is shown by EPBP in this investigation, is defined by Eq. (20) [57]:

$$
E P B P=\frac{E_{\text {material_to_delivery }}}{E_{P V}}
$$

The numerator in Eq. (20) is the energy consumed during the process of preparing material to delivery to the end-user. In order to calculate this parameter, the information reported in [58] is utilized. The denominator is also the amount of electricity bought from the network in case there were not any PV technologies for power generation. It could be determined based on the governing equations presented in part 3.1.

\section{Results and discussion}

In this study, a $150 \mathrm{~W}$ poly crystalline module, produced by Yingly company is chosen as the studied module. It is assumed that this module is installed in city Tehran, Iran from January, which is the beginning of the year. The information about the module, as well as the location of the case study is completely found in the previous study of the research team [59].

The results are provided in Fig. 2. This figure demonstrates that by increasing the inlet water mass flow rate, the absorbed heat from the solar module goes up. Therefore, a higher amount of power is 
generated by the PV system. Therefore, the produced power in one internal, and as a result, the generated electricity by solar module [60] during a period has an upward trend. The amount of energy required for producing the installed capacity of a solar module is constant (the numerator in Eq. (20)). The more electricity is produced, the higher denominator is, which is accompanied by a lower EPBP.

As per Fig. 2, using water flow cooling leads to a considerable improvement in EPBP. When no cooling is utilized, EPBP is 8.88 years. By applying the water flow cooling it decreases and reaches 7.85 years when the inlet water flow rate is $0.005 \mathrm{~kg} . \mathrm{s}^{-1}$. An almost linear trend is observed until the inlet mass flow rate of $0.015 \mathrm{~kg} . \mathrm{s}^{-1}$, where EPBP 6.26 years. It is 29.50 and $20.25 \%$ lower than the corresponding values for the two previously indicated water inlet flow rates, respectively.

However, the linear trend changes and the decrease rate declines. The same increment in the mass flow rate, i.e., $0.010 \mathrm{~kg} . \mathrm{s}^{-1}$ results in only 0.28 years lower EPBP. In other words, EBPB reaches 5.98 years when the inlet water mass flow rate becomes $0.025 \mathrm{~kg} . \mathrm{s}^{-1}$. It indicates that the changes in the range of 0.005 to $0.015 \mathrm{~kg} . \mathrm{s}^{-1}$, i.e., 1.59 years $(7.85-6.26)$, is 5.68 times bigger than the corresponding one in the range of 0.015 to $0.025 \mathrm{~kg} \cdot \mathrm{s}^{-1}$ for the inlet water flow rate, which is 0.28 years.

The obtained outcome reveals that increasing the inlet water flow is reasonable only in the linear range, and after that, EPBP does not change significantly; only the water evaporation and water circulation cost have upward trends. Consequently, an optimum limit for the inlet water mass flow rate could be considered, which is around $0.015 \mathrm{~kg} \cdot \mathrm{s}^{-1}$ for the investigated case study.

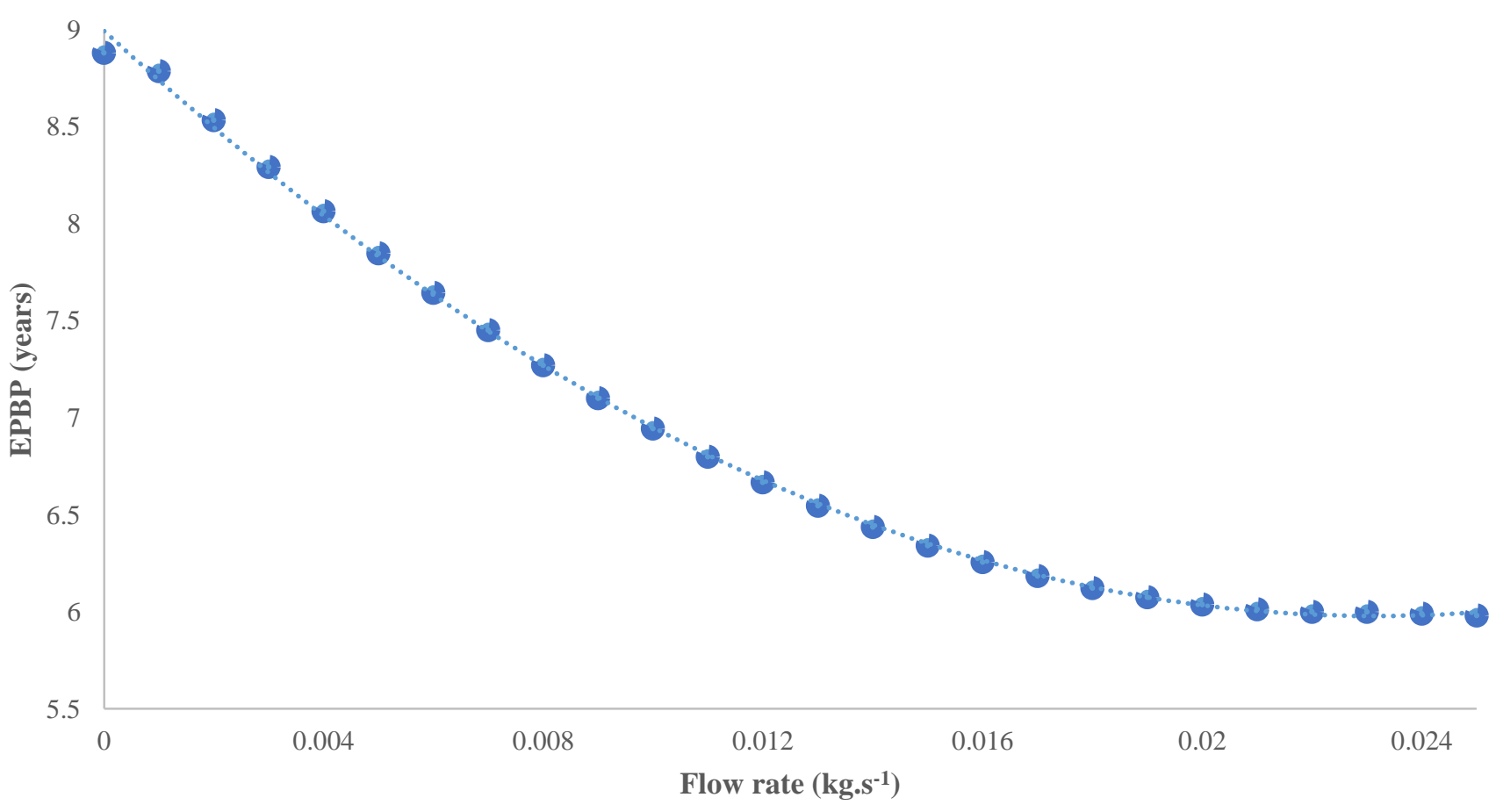

Fig. 2. Impact of water flow rate on EPBP

\section{Conclusions}

The impact of the inlet water mass flow rate on the energy payback period (EPBP) of a system 
with water flow cooling technology was found through conducting a parametric study. A $150 \mathrm{~W}$ poly crystalline module is considered to be installed in city Tehran, Iran. The system was simulated using a developed mathematical model. The results demonstrated that there was an optimum value for inlet water mass flow rate. It is the point the linear decrement turned into approaching a constant limit. For the investigated case-study the optimum value was found to be $0.015 \mathrm{~kg} \cdot \mathrm{s}^{-1}$. Adjusting the water flow rate to the optimum condition offered the EPBP of 6.26 years.

\section{References}

[1] Razmjoo, Armin, Meysam Majidi Nezhad, Lisa Gakenia Kaigutha, Mousa Marzband, Seyedali Mirjalili, Mehdi Pazhoohesh, Saim Memon, Mehdi A. Ehyaei, and Giuseppe Piras. "Investigating Smart City Development Based on Green Buildings, Electrical Vehicles and Feasible Indicators." Sustainability 13, no. 14 (2021): 7808. https://doi.org/10.3390/su13147808

[2] Tjahjono, Tri, Mehdi Ali Ehyaei, Abolfazl Ahmadi, Siamak Hoseinzadeh, and Saim Memon. "Thermo-Economic Analysis on Integrated CO2, Organic Rankine Cycles, and NaClO Plant Using Liquefied Natural

Gas." Energies 14, no. 10 (2021): 2849. https://doi.org/10.3390/en14102849

[3] Bensafi, Mohammed, Houari Ameur, Noureddine Kaid, Siamak Hoseinzadeh, Saim Memon, and Davide Astiaso Garcia. "Thermophysics Analysis of Office Buildings with a Temperature-Humidity Coupling Strategy Under Hot-Arid Climatic Conditions." International Journal of Thermophysics 42, no. 8 (2021): 1-20. https://doi.org/10.1007/s10765-021-02858-1

[4] Memon, S., T. Katsura, A. Radwan, S. Zhang, A. A. Serageldin, E. M. Abo-Zahhad, S. Sergey et al. "Modern eminence and concise critique of solar thermal energy and vacuum insulation technologies for sustainable lowcarbon infrastructure." International Journal of Solar Thermal Vacuum Engineering 1, no. 1 (2020): 52-71. ISSN online (2716-6953).

https://doi.org/10.37934/stve.1.1.5271

[5] Katsura, Takao, Saim Memon, Ali Radwan, Makoto Nakamura, and Katsunori Nagano. "Thermal performance analysis of a new structured-core translucent vacuum insulation panel in comparison to vacuum glazing: Experimental and theoretically validated analyses." Solar Energy 199 (2020): 326-346. https://doi.org/10.1016/j.solener.2020.02.030

[6] Radwan, Ali, Takao Katsura, Saim Memon, Ahmed A. Serageldin, Makoto Nakamura, and Katsunori Nagano. "Thermal and electrical performances of semi-transparent photovoltaic glazing integrated with translucent vacuum insulation panel and vacuum glazing." Energy Conversion and Management 215 (2020): 112920. https://doi.org/10.1016/i.enconman.2020.112920

[7] Ahmed, Mostafa, Ali Radwan, Ahmed Serageldin, Saim Memon, Takao Katsura, and Katsunori Nagano. "Thermal Analysis of a New Sliding Smart Window Integrated with Vacuum Insulation, Photovoltaic, and Phase Change Material." Sustainability 12, no. 19 (2020): 7846. https://doi.org/10.3390/su12197846

[8] Memon, Saim, Yueping Fang, Essam Mohamed Abo-Zahhad, O. Abdelrehim, Mohamed R. Elmarghany, Abdul Rashid Memon, Shanwen Zhang, and Amos Darko. "Factors influencing the performance parameters of vacuum glazed smart windows to net zero energy buildings." International Journal of Solar Thermal Vacuum Engineering 2, no. 1 (2020): 1-18. https://doi.org/10.37934/stve.2.1.118

[9] Memon, Saim, Yueping Fang, and Philip C. Eames. "The influence of low-temperature surface induction on evacuation, pump-out hole sealing and thermal performance of composite edge-sealed vacuum insulated glazing." Renewable energy 135 (2019): 450-464. https://doi.org/10.1016/j.renene.2018.12.025

[10] Memon, Saim. "Design, fabrication and performance analysis of vacuum glazing units fabricated with low and high temperature hermetic glass edge sealing materials." PhD diss., Loughborough University, 2013. https://dspace.lboro.ac.uk/2134/14562

[11] Memon, Saim, Farukh Farukh, and Karthikeyan Kandan. "Effect of cavity vacuum pressure diminution on thermal performance of triple vacuum glazing." Applied Sciences 8, no. 9 (2018): 1705. https://doi.org/10.3390/app8091705 
[12] Memon, Saim. "Experimental measurement of hermetic edge seal's thermal conductivity for the thermal transmittance prediction of triple vacuum glazing." Case studies in thermal engineering 10 (2017): 169-178. https://doi.org/10.1016/i.csite.2017.06.002

[13] Memon, Saim, Farukh Farukh, Philip C. Eames, and Vadim V. Silberschmidt. "A new low-temperature hermetic composite edge seal for the fabrication of triple vacuum glazing." Vacuum 120 (2015): 73-82. https://doi.org/10.1016/i.vacuum.2015.06.024

[14] Memon, Saim, and Philip C. Eames. "Predicting the solar energy and space-heating energy performance for solid-wall detached house retrofitted with the composite edge-sealed triple vacuum glazing." Energy Procedia 122 (2017): 565-570. https://doi.org/10.1016/i.egypro.2017.07.419

[15] Memon, Saim. "Analysing the potential of retrofitting ultra-low heat loss triple vacuum glazed windows to an existing UK solid wall dwelling." International Journal of Renewable Energy Development (IJRED) 3, no. 3 (2014): 161-174. https://doi.org/10.14710/ijred.3.3.161-174

[16] Memon, Saim, and Philip C. Eames. "Heat load and solar gain prediction for solid wall dwellings retrofitted with triple vacuum glazing for selected window to wall area ratios." In World Renewable Energy Forum, WREF 2012, vol. 6, pp. 4636-4643. ASES, 2012. ISBN: 9781622760923

[17] Fang, Yueping, Saim Memon, Jingqing Peng, Mark Tyrer, and Tingzhen Ming. "Solar thermal performance of two innovative configurations of air-vacuum layered triple glazed windows." Renewable Energy 150 (2020): 167-175. https://doi.org/10.1016/i.renene.2019.12.115

[18] Memon, Saim, and Philip C. Eames. "Solar energy gain and space-heating energy supply analyses for solid-wall dwelling retrofitted with the experimentally achievable U-value of novel triple vacuum glazing." Journal of Daylighting 4, no. 1 (2017): 15-25. https://doi.org/10.15627/id.2017.2

[19] Memon, Saim. "Thermal Conductivity Measurement of Vacuum Tight Dual-Edge Seal for the Thermal Performance Analysis of Triple Vacuum Glazing." Impact of Thermal Conductivity on Energy Technologies (2018): 133. http://dx.doi.org/10.5772/intechopen.74255

[20] Memon, Saim. "Design, development and thermal performance analysis of ultra-low heat loss triple vacuum glazing." In Solar World Congress 2017-Innovation for the 100\% renewable energy transformation. Abu Dhabi. (2017) ISBN 978-3-981 465 9-7-6. https://doi.org/10.18086/swc.2017.15.04

[21] Memon, Saim. "Investigating energy saving performance interdependencies with retrofit triple vacuum glazing for use in UK dwelling with solid walls, Sustainable Development on Building and Environment." In Sustainable Development on Building and Environment: Proceedings of the 7th International Conference, 2015. ISBN-13: 978-0993120701.

[22] Miao, Hong, Lingcong Zhang, Sixing Liu, Shanwen Zhang, Saim Memon, and Bi Zhu. "Laser Sealing for Vacuum Plate Glass with PbO-TiO2-SiO2-RxOy Solder." Sustainability 12, no. 8 (2020): 3118. https://doi.org/10.3390/su12083118

[23] Zhang, Shanwen, Min Kong, Saim Memon, Hong Miao, Yanjun Zhang, and Sixing Liu. "Thermal Analysis of a New Neutron Shielding Vacuum Multiple Glass." Sustainability 12, no. 8 (2020): 3083. https://doi.org/10.3390/su12083083

[24] Memon, Saim, and Philip C. Eames. "Design and development of lead-free glass-metallic vacuum materials for the construction and thermal performance of smart fusion edge-sealed vacuum glazing." Energy and Buildings (2020): 110430. https://doi.org/10.1016/j.enbuild.2020.110430

[25] Zhang, Shanwen, Min Kong, Hong Miao, Saim Memon, Yanjun Zhang, and Sixing Liu. "Transient temperature and stress fields on bonding small glass pieces to solder glass by laser welding: Numerical modelling and experimental validation." Solar Energy 209 (2020): 350-362.

https://doi.org/10.1016/i.solener.2020.09.014

[26] Radwan, Ali, Takao Katsura, Saim Memon, Essam M. Abo-Zahhad, O. Abdelrehim, Ahmed A. Serageldin, Mohamed R. Elmarghany, Asmaa Khater, and Katsunori Nagano. "Development of a new vacuum-based photovoltaic/thermal collector, and its thermal and exergy analyses." Sustainable Energy \& Fuels 4, no. 12 (2020): 6251-6273. https://doi.org/10.1039/DOSE01102A 
[27] Memon, Saim. 2021. "The Scope of Advanced Smart Vacuum Insulation Technologies for Net-Zero Energy Buildings", Sustainable Energy Development and Innovation, WREC 2020. Springer Nature, https://doi.org/10.1007/978-3-030-76221-6

[28] Abo-Zahhad, Essam M., Shinichi Ookawara, Ali Radwan, Saim Memon, Yue Yang, M. F. El-Kady, and A. H. ElShazly. "Flow boiling in a four-compartment heat sink for high-heat flux cooling: A parametric study." Energy Conversion and Management 230 (2021): 113778. https://doi.org/10.1016/i.enconman.2020.113778

[29] Memon, Saim, Olatunde Muisdeen Lawal, Sumair Ahmed Tariq, and Bilal Khalid. "Wave energy in the UK: Current scope, challenges and prognostications." International Journal of Solar Thermal Vacuum Engineering 2, no. 1 (2020): 59-78. https://doi.org/10.37934/stve.2.1.4058

[30] Makeen, Peter, Hani A. Ghali, and Saim Memon. "Experimental and Theoretical Analysis of the Fast Charging Polymer Lithium-Ion Battery Based on Cuckoo Optimization Algorithm (COA)." IEEE Access 8 (2020): 140486140496.

https://doi.org/10.1109/ACCESS.2020.3012913

[31] Khan, Asif, Saim Memon, and T. P. Sattar. "Integration and management of solar energy for electric vehicle charging station." In Solar World Congress 2017-Innovation for the 100\% renewable energy transformation. Abu Dhabi, (2017). ISBN 978-3-981 465 9-7-6. https://doi.org/10.18086/swc.2017.16.03

[32] Khan, Asif, Saim Memon, and Tariq Pervez Sattar. "Analyzing integrated renewable energy and smart-grid systems to improve voltage quality and harmonic distortion losses at electric-vehicle charging stations." IEEE Access 6 (2018): 26404-26415.

https://doi.ord/10.1109/ACCESS.2018.2830187

[33] Makeen, Peter, Saim Memon, M. A. Elkasrawy, Sameh O. Abdullatif, and Hani A. Ghali. "Smart green charging scheme of centralized electric vehicle stations." International Journal of Green Energy (2021): 1-9. https://doi.org/10.1080/15435075.2021.1947822

[34] Makeen, Peter, Hani Ghali, and Saim Memon. "Controllable Electric Vehicle Fast Charging Approach Based on Multi-Stage Charging Current Methodology." In 2020 IEEE International Conference on Power and Energy (PECon), pp. 398-403. IEEE, 2020. https://doi.org/10.1109/PECon48942.2020.9314471

[35] Alayi, Reza, Farhad Zishan, Mahdi Mohkam, Siamak Hoseinzadeh, Saim Memon, and Davide Astiaso Garcia. "A Sustainable Energy Distribution Configuration for Microgrids Integrated to the National Grid Using Back-toBack Converters in a Renewable Power System." Electronics 10, no. 15 (2021): 1826. https://doi.org/10.3390/electronics10151826

[36] Memon, Saim, Maekele Mihreteab, Takao Katsura, Ali Radwan, Shanwen Zhang, Ahmed A. Serageldin, and Essam M. Abo-Zahhad. "Experimental and theoretical performance evaluation of parabolic trough mirror as solar thermal concentrator to thermoelectric generators." International Journal of Solar Thermal Vacuum Engineering 1, no. 1 (2020): 22-38. ISSN online (2716-6953).

https://doi.org/10.37934/stve.1.1.2238

[37] Memon, Saim. "Advanced Thermoelectric Materials for Energy Harvesting Applications." .IntechOpen Publisher, London, ISBN: 978-1-78984-529-7, (2020). https://doi.org/10.5772/intechopen.77430

[38] Memon, Saim, and Khawaja Noman Tahir. "Experimental and analytical simulation analyses on the electrical performance of thermoelectric generator modules for direct and concentrated quartz-halogen heat harvesting." Energies 11, no. 12 (2018): 3315.

https://doi.org/10.3390/en11123315

[39] Memon, Saim. "Introductory Chapter: Introduction to Advanced Thermoelectric Materials for Energy Harvesting Applications", Advanced Thermoelectric Materials for Energy Harvesting Applications, IntechOpen, London. (2019).

https://doi.org/10.5772/intechopen.89640

[40] Khan, Asif, and Saim Memon. "Effect of hot-arid climatic solar energy on monocrystalline photovoltaic performance in Pakistan." International Journal of Solar Thermal Vacuum Engineering 2, no. 1 (2020): 19-39. https://doi.org/10.37934/stve.2.1.1939

[41] Memon, Saim, Gemeda Olani Nemera, and Tochukwu Israel Nwokeji. "Manifestations of carbon capturestorage and ambivalence of quantum-dot \& organic solar cells: An indispensable abridged review." International Journal of Solar Thermal Vacuum Engineering 2, no. 1 (2020): 40-58. https://doi.org/10.37934/stve.2.1.4058 
[42] Abo-Zahhad, Essam Mohamed, A. S. Hammad, Ali Radwan, Saim Memon, A. H. El-Shazly, and M. F. El-Kady. "Dye removal with magnetic graphene nanocomposite through micro reactors." International Journal of Solar Thermal Vacuum Engineering 2, no. 1 (2020): 79-94.

https://doi.org/10.37934/stve.2.1.7994

[43] [3] Sundar, L. Syam, Yihun Tefera Sintie, Zafar Said, Manoj K. Singh, V. Punnaiah, and Antonio CM Sousa. "Energy, efficiency, economic impact, and heat transfer aspects of solar flat plate collector with Al2O3 nanofluids and wire coil with core rod inserts." Sustainable Energy Technologies and Assessments 40 (2020): 100772.

https://doi.org/10.1016/i.seta.2020.100772

[44] Sundar, L. Syam, A. Kirubeil, V. Punnaiah, Manoj K. Singh, and Antonio CM Sousa. "Effectiveness analysis of solar flat plate collector with Al2O3 water nanofluids and with longitudinal strip inserts." International Journal of Heat and Mass Transfer 127 (2018): 422-435. https://doi.org/10.1016/j.ijheatmasstransfer.2018.08.025

[45] Javidan, Mohammad, and Ali Jabari Moghadam. "Experimental investigation on thermal management of a photovoltaic module using water-jet impingement cooling." Energy Conversion and Management 228 (2021): 113686. https://doi.org/10.1016/i.enconman.2020.113686

[46] Shahverdian, Mohammad Hassan, Ali Sohani, Hoseyn Sayyaadi, Saman Samiezadeh, Mohammad Hossein Doranehgard, Nader Karimi, and Larry KB Li. "A dynamic multi-objective optimization procedure for water cooling of a photovoltaic module." Sustainable Energy Technologies and Assessments 45 (2021): 101111. https://doi.org/10.1016/i.seta.2021.101111

[47] da Silva, Vinícius Oliveira, Julio Romel Martinez-Bolanos, Raphael Bertrand Heideier, André Luiz Veiga Gimenes, Miguel Edgar Morales Udaeta, and Marco Antônio Saidel. "Theoretical and experimental research to development of water-film cooling system for commercial photovoltaic modules." IET Renewable Power Generation 15, no. 1 (2021): 206-224. https://doi.org/10.1049/rpg2.12017

[48] Luboń, Wojciech, Grzegorz Pełka, Mirosław Janowski, Leszek Pająk, Michał Stefaniuk, Jarosław Kotyza, and Paweł Reczek. "Assessing the impact of water cooling on PV modules efficiency." Energies 13, no. 10 (2020): 2414. https://doi.org/10.3390/en13102414

[49] Kabeel, A. E., Mohamed Abdelgaied, and Ravishankar Sathyamurthy. "A comprehensive investigation of the optimization cooling technique for improving the performance of PV module with reflectors under Egyptian conditions." Solar Energy 186 (2019): 257-263. https://doi.org/10.1016/j.solener.2019.05.019

[50] Tashtoush, Bourhan, and Ali Al-Oqool. "Factorial analysis and experimental study of water-based cooling system effect on the performance of photovoltaic module." International journal of environmental science and technology 16, no. 7 (2019): 3645-3656. https://doi.org/10.1007/s13762-018-2044-9

[51] Mah, Chia-Yi, Boon-Han Lim, Chee-Woon Wong, Ming-Hui Tan, Kok-Keong Chong, and An-Chow Lai. "Investigating the performance improvement of a photovoltaic system in a tropical climate using water cooling method." Energy Procedia 159 (2019): 78-83. https://doi.org/10.1016/i.egypro.2018.12.022

[52] Basrawi, Firdaus, Yeong C. Leon, Thamir K. Ibrahim, Mohd Hazwan Yusof, A. A. Razak, Shaharin Anuar Sulaiman, and Takanobu Yamada. "Experimental Analysis on the Effect of Area of Surface Cooling for a WaterCooled Photovoltaic." In MATEC Web of Conferences, vol. 225, p. 01011. EDP Sciences, 2018. https://doi.org/10.1051/matecconf/201822501011

[53] Nižetić, Sandro, Duje Čoko, A. Yadav, and Filip Grubišić-Čabo. "Water spray cooling technique applied on a photovoltaic panel: The performance response." Energy conversion and management 108 (2016): 287-296. https://doi.org/10.1016/j.enconman.2015.10.079

[54] Sohani, Ali, Mohammad Hassan Shahverdian, Hoseyn Sayyaadi, Siamak Hoseinzadeh, Saim Memon, Giuseppe Piras, and Davide Astiaso Garcia. "Energy and Exergy Analyses on Seasonal Comparative Evaluation of Water Flow Cooling for Improving the Performance of Monocrystalline PV Module in Hot-Arid Climate." Sustainability 13, no. 11 (2021): 6084. https://doi.org/10.3390/su13116084

[55] Shahverdian, Mohammad Hassan, Ali Sohani, and Hoseyn Sayyaadi. "Water-energy nexus performance investigation of water flow cooling as a clean way to enhance the productivity of solar photovoltaic modules." Journal of Cleaner Production (2021): 127641. 
https://doi.org/10.1016/j.jclepro.2021.127641

[56] Sohani, Ali, Hoseyn Sayyaadi, Mohammad Hossein Doranehgard, Sandro Nizetic, and Larry KB Li. "A method for improving the accuracy of numerical simulations of a photovoltaic panel." Sustainable Energy Technologies and Assessments 47 (2021): 101433.

https://doi.org/10.1016/i.seta.2021.101433

[57] Wang, Wenli, Yongsheng Liu, Xinfang Wu, Yan Xu, Wenying Yu, Chunjiang Zhao, and Yunbo Zhong. "Environmental assessments and economic performance of BAPV and BIPV systems in Shanghai." Energy and Buildings 130 (2016): 98-106.

https://doi.org/10.1016/i.enbuild.2016.07.066

[58] Dai Prá, Léa Beatriz, João Batista Dias, and Amanda Gonçalves Kieling. "Comparison between the energy required for production of PV module and the output energy throughout the product life time." Journal of Energy and Power Engineering 9 (2015): 592-597.

[59] Sohani, Ali, and Hoseyn Sayyaadi. "Employing genetic programming to find the best correlation to predict temperature of solar photovoltaic panels." Energy Conversion and Management 224 (2020): 113291. https://doi.org/10.1016/i.enconman.2020.113291

[60] Radwan, Ali, Takao Katsura, Saim Memon, Essam M. Abo-Zahhad, Ahmed A. Serageldin, and Katsunori Nagano. "Analysis of a vacuum-based photovoltaic thermal collector." Energy Reports 6 (2020): 236-242.

https://doi.org/10.1016/i.egyr.2020.11.255 